\title{
Impact of Physical Training on the Ultrastructure of Midthigh Muscle in Normal Subjects and in Patients Treated with Glucocorticoids
}

\author{
F. F. Horber," H. Hoopeler," J. R. Scheidegger," B. E. Grünig," H. Howald,' and F. J. Frey* \\ ${ }^{*}$ Medizinische Poliklinik, Inselspital, 3010 Berne; ${ }^{\ddagger}$ Department of Anatomy, University of Berne, 3010 Berne; ${ }^{\top}$ Research Institute of the \\ Swiss School for Physical Education and Sports, 2532 Magglingen; ${ }^{8}$ Department of Diagnostic Radiology, Inselspital, 3010 Berne; \\ "Department of Orthopedic Surgery, Inselspital, 3010 Berne, Switzerland
}

\begin{abstract}
Exercise-training might be a logical method to reverse muscle atrophy and weakness in patients treated with glucocorticoids. The purpose of the present investigation was to establish whether a treatment with low dose prednisone $(10 \pm 2.9 \mathrm{mg} / \mathrm{d})$ modulates the effect of a moderate strength type isokinetic training during 7 wk (21 sessions of $20 \mathrm{~min}$ ) on "muscle efficiency" (power output/muscle mass) and on concomitant changes in ultrastructure of the thigh muscle measured by quantitative electron-microscopic morphometry. Training caused a similar increase in "muscle efficiency" in patients on prednisone $(n=9)$ as in normal volunteers $(n=9)$. In normal subjects the increase in muscle efficiency was associated with an increase in sarcoplasm, whereas in patients on prednisone the functional improvement was associated with an increase in sarcoplasm, capillaries, and mitochondria content. Thus, a therapy with low dose prednisone does not abrogate training-induced improvement of muscle efficiency but modulates the ultrastructural response of the muscle to the training.
\end{abstract}

\section{Introduction}

The development of muscle weakness and atrophy is a well known complication of therapy with exogenous glucocorticoids and Cushing's disease $(1,2)$. It is probably the most common form of drug-induced myopathy encountered in clinical practice (3). In the 1960s qualitative ultrastructural analyses of mitochondria have been performed in muscle cells of patients treated with glucocorticoids. These analyses revealed numerous alterations of mitochondria such as "enlargement," "aggregation," or "vacuolation" (4-6). An analysis of the quadriceps muscle of rats treated with hydrocortisone showed increased subsarcolemmal mitochondria (7), a finding that we have corroborated in patients treated with prednisone (8). In addition, in the biopsies from these patients treated with prednisone, a decreased myofibrillar and an increased intracellular lipid content was found. In all these previously reported investigations about the ultrastructure of muscle cells in animals or humans treated with glucocorticoids, the methods used allowed only a qualitative analysis (4-7) or a quantitative analysis (8) restricted to the small tissue sample of a muscle biopsy. One of the purposes of the present

\footnotetext{
Address reprint requests to Dr. Frey, Medizinische Poliklinik, Freiburgstrasse 3, 3010 Berne, Switzerland.

Received for publication 26 June 1986.
}

J. Clin. Invest.

(c) The American Society for Clinical Investigation, Inc.

0021-9738/87/04/1181/10 $\$ 1.00$

Volume 79, April 1987, 1181-1190 investigation was not only to quantify the ultrastructure within the biopsy specimen, but to extend these quantitative morphometric measures to the total thigh muscle (9). Therefore, a quantitative morphometric electron microscopic analysis of thigh muscle biopsies was combined, for the first time in a disease state, with a quantitative measure of total thigh muscle mass as assessed by computed tomography (CT). ${ }^{1}$

Ultrastructural abnormalities of muscle cells might be functionally relevant. To get insight into the functional relevance of such abnormalities, quantitative thigh muscle function has to be assessed concomitantly. We have demonstrated that patients treated with prednisone exhibit a decreased thigh muscle mass (as assessed by CT [10,11]) and thigh muscle function (assessed by an isokinetic dynamometer [10]) and that with a regular isokinetic training thigh muscle mass and function can be normalized in these patients treated with glucocorticoids (12). In the present investigation the influence of an isokinetic training on the total ultrastructural components of the thigh muscle was assessed. The observed changes were correlated with quantitative changes of muscle function in order to establish whether isokinetic training affects muscle function and muscle morphology differently in patients on prednisone than in healthy volunteers.

\section{Methods}

Patients and normal subjects. Nine clinically stable renal transplant patients were studied (Table I). All had been transplanted at least 16 mo before the investigation (median: $60 \mathrm{mo}$, range 16-105 mo). The mean $( \pm \mathrm{SD})$ value of plasma creatinine was $120 \pm 30 \mu \mathrm{mol} / \mathrm{liter}$. No patients with anemia, aseptic necrosis of the femoral head, or with joint diseases of the lower extremities were included. Prednisone was administered to all patients (actual dose, $10.3 \pm 2.9$ [ $\pm \mathrm{SD}] \mathrm{mg} / \mathrm{d}$, last year before the investigation: $10.9 \pm 3.7 \mathrm{mg} / \mathrm{d}$ ). In addition the patients were receiving azathioprine and various other drugs such as furosemide, calcium antagonists, and $\beta$-adrenergic blocking agents. No drug dosage was changed during the training period. All patients were rehabilitated, in that after transplantation they had resumed their professional and private activities. However, only one patient underwent regular physical training.

For comparison, nine subjects not undergoing regular physical training, were studied (Table I). Their mean ( \pm SD) plasma creatinine level was $95 \pm 20 \mu \mathrm{mol} / \mathrm{liter}$. The patients and normal subjects were matched for sex, age, body weight, body height, and body mass index (Table I).

All subjects gave informed consent. The protocol was approved by the Committee on Human Research at our Institution.

Training protocol. The subjects (Table I) were trained isokinetically using the Cybex II (Cybex, Div. of Lumex, Inc., Ronkonkoma, NY)

1. Abbreviations used in this paper: $\mathrm{C}$, capillary; CT, computed tomography; EM, electron microscopy; $f_{\text {fat }}(\%), \%$ total intramuscular fat; $\mathbf{H}_{\text {mix }}$, mean density of the thigh muscle measured in each subject; $H_{\text {mus }}$, mean density of the thigh muscle in 10 normal volunteers; HU, Hounsfield unit; $M$, mitochondria; $N$, nucleus of muscle cell; Nm, Newton-meter; $\mathrm{S}$, subsarcolemmal region; $\dot{V O}_{2}$ peak; peak oxygen uptake capacity. 
Table I. Subjects' Characteristics, Midthigh Components, and Muscle Function in Normal Subjects and in Patients Treated with Prednisone Before and After Training

\begin{tabular}{|c|c|c|c|c|c|c|}
\hline & \multicolumn{3}{|l|}{ Normal subjects } & \multicolumn{3}{|c|}{ Prednisone-treated patients } \\
\hline & Before & After & $\begin{array}{l}P \text { value before } \\
\text { vs. after training }\end{array}$ & Before & After & $\begin{array}{l}P \text { value before } \\
\text { vs. after training }\end{array}$ \\
\hline \multicolumn{7}{|l|}{ Subjects' characteristics } \\
\hline n $(\$ / \delta)$ & \multicolumn{2}{|c|}{$9(5 / 4)$} & & \multicolumn{2}{|c|}{$9(5 / 4)$} & \\
\hline Age (yr) & \multicolumn{2}{|c|}{$33.6 \pm 6.3$} & & \multicolumn{2}{|c|}{$33.9 \pm 9.9$} & \\
\hline Body weight $(\mathbf{k g})$ & \multicolumn{2}{|c|}{$61.3 \pm 9.6$} & & \multicolumn{2}{|c|}{$59.0 \pm 8.8$} & \\
\hline Body height (cm) & \multicolumn{2}{|c|}{$164.2 \pm 10.6$} & & \multicolumn{2}{|c|}{$163.7 \pm 10.1$} & \\
\hline Body mass index $\left(\mathrm{kg} \mathrm{m}^{-2}\right)$ & \multicolumn{2}{|c|}{$22.6 \pm 2.3$} & & \multicolumn{2}{|c|}{$22.4 \pm 2.3$} & \\
\hline \multicolumn{7}{|l|}{ Midthigh components (CT) } \\
\hline Total thigh area, $\mathrm{cm}^{2}$ & $216.1 \pm 22.7$ & $220.2 \pm 27.6$ & NS & $181.4 \pm 17.3$ & $184.1 \pm 16.6$ & NS \\
\hline Thigh muscle area, $\mathrm{cm}^{2}$ & $127.5 \pm 30.1$ & $133.1 \pm 28.9$ & $<0.01$ & $100.4 \pm 22.1$ & $107.1 \pm 24.2$ & $<0.005$ \\
\hline Thigh fat area, $\mathrm{cm}^{2}$ & $81.7 \pm 45.1$ & $80.0 \pm 47.2$ & NS & $75.3 \pm 26.5$ & $71.0 \pm 24.1$ & $<0.02$ \\
\hline Fat/muscle ratio & $0.74 \pm 0.53$ & $0.69 \pm 0.50$ & $<0.001$ & $0.84 \pm 0.38$ & $0.75 \pm 0.34$ & $<0.001$ \\
\hline \multicolumn{7}{|l|}{ Muscle function (Cybex II) } \\
\hline Peak torque at $60^{\circ} / \mathrm{s}, \mathrm{Nm}$ & $236 \pm 71$ & $289 \pm 99$ & $<0.005$ & $207 \pm 61$ & $237 \pm 65$ & $<0.005$ \\
\hline Total work output at $180^{\circ} / \mathrm{s}, J$ & $3,563 \pm 1,396$ & $4,584 \pm 1,545$ & $<0.001$ & $2,712 \pm 579$ & $3,587 \pm 724$ & $<0.001$ \\
\hline
\end{tabular}

Values are the mean \pm SD.

three times per week for $7 \mathrm{wk}$. Isokinetic training was defined as exercising at a constant velocity of joint motion. The training sessions were structured as follows: (a) A 5-min warm-up on an isokinetic bicycle $(90 \mathrm{rpm}$, $600-800 \mathrm{~kg} / \mathrm{min}$ ). (b) The thigh muscle of one leg was trained with 8 maximal flexions and extensions of the knee at an angular velocity of $60 \%$, repeated 8-10 times, with $30 \mathrm{~s}$ of relief between each workbout. (c) After a pause of $3 \mathrm{~min}$, the thigh muscle was exercised to the point of exhaustion at an angular velocity of $180^{\circ} / \mathrm{s}$, four times, with $45 \mathrm{~s}$ of relief between each workbout. Exhaustion was reached when the subjects were not able to produce any measurable torque.

To assess the effect of this thigh muscle training lasting $7 \mathrm{wk}$, the following measurements were performed before and after the training period: CT of the thigh, thigh muscle function as assessed by Cybex II, peak oxygen uptake ( $\dot{V}_{2}$ peak), ultrastructural morphometry on biopsies of the vastus lateralis muscle.

CT. CT (Somatom SF, Siemens Corp., Erlangen, FRG) was performed on the thigh halfway between the major trochanter and the knee joint space. The subjects were examined in the supine position, and the thigh muscle was relaxed. Radiographic factors were a cycle time of $5 \mathrm{~s}$, $125 \mathrm{kV}, 230 \mathrm{~mA}$ and a slice thickness of $10 \mathrm{~mm}$. Evaluations were made at a window width of 512 and a level between 10 and 40 to achieve good contrast between muscle, bone, and fat. The density, expressed in Hounsfield units, of the thigh muscle $\left(\mathrm{H}_{\text {mix }}\right)$ was assessed by means of computerized densitometry (Evaluscop, Siemens Corp.).

Computerized planimetry (Electronic Digitizing Tablet, Summagraphics, Fairfield, CT) linked to a Commodore microcomputer (model 2001, Commodore, Berne, Switzerland) was used to quantify the following areas: total thigh area, bone area, muscle area, and fat area (equals total area minus bone and muscle areas). To estimate the variability of the computerized planimetry of the muscle area, the radiographs were analyzed twice on different occasions and the coefficient of variation for paired observation was found to be: $0.24 \%(n=10)$. The investigator performing the morphometric analysis was blind concerning the origin of the radiographs. The muscle area assessed by computed tomography comprise muscle tissue and intercellular fat deposits. In order to quantitate the true muscle area (without intercellular fat) Grindrod et al. (13) proposed a method for estimating the percentage of fat within the muscle area:

$f_{\text {fat }}(\%)=\frac{H_{\text {mus }}-H_{\text {mix }}}{H_{\text {mus }}-H_{\text {fat }}} \times 100$ where $f_{\text {fat }}(\%)$ means total intramuscular fat, $H_{\text {fat }}$ the normal fat density, $\mathrm{H}_{\text {mus }}$ the normal muscle density and $\mathrm{H}_{\text {mix }}$ the measured mean density of the thigh muscle in each subject investigated. An estimate of the normal muscle density $\left(\mathrm{H}_{\text {mus }}\right)$ was obtained by measuring in 10 normal volunteers with no evidence of any disease or training the muscle density of $1 \mathrm{~cm}^{2}$ of the vastus lateralis muscle at the same anatomic localization. The normal fat density $\left(\mathrm{H}_{\mathrm{fat}}\right)$ was obtained by measuring the density of $1 \mathrm{~cm}^{2}$ of subcutaneous fat tissue at the same anatomic localization. In the present investigation the percentage of fat calculated according to the method of Grindrod (13) was subtracted from the total muscle area obtained by computed tomography in order to estimate the true muscle area.

Assessment of muscle function. In all 18 subjects thigh muscle performance was assessed using a Cybex II dual channel system isokinetic dynamometer (Cybex, Division of Lumex, Inc.) interfaced to a Cybex data reduction computer. This device consists of a moveable lever arm, controlled by an electronic servomotor that can be set at any velocity from 0 to $300^{\circ} / \mathrm{s} \mathrm{(14).} \mathrm{The} \mathrm{lever} \mathrm{arm} \mathrm{is} \mathrm{attached} \mathrm{to} \mathrm{the} \mathrm{subject's} \mathrm{leg,} \mathrm{and}$ any attempt to accelerate beyond the preset speed is resisted. The device provides an accomodating resistance throughout the range of motion of the tested leg, while a hydraulic system measures the torque, the angular analogue of force. The torque is expressed in Newton-meters $(\mathrm{Nm})$. The Cybex II was calibrated against known loads. To restrict the contraction to the thigh muscle as best as possible, the subjects were strapped to the seat at the thigh, hip, and chest. The axis of the dynamometer was aligned at the pivot of the knee joint. A lever was connected to the tibia at ankle level, and maximal knee extensions and flexions were performed from 90 to $0^{\circ}\left(0^{\circ}\right.$ equals full knee extension). The subjects were verbally excouraged to exert maximal muscular force throughout the $90^{\circ}$ arc of movement. Before subjects were tested, they performed a 5-min standard warm-up on a bicycle ergometer.

In order to assess the performance changes during the training period, two isokinetic tests were administered: (a) Maximal peak torque of each leg as reached during five maximal knee extensions and flexions at angular velocities of $60^{\circ} / \mathrm{s}$. (b) Total work output measured during 25 repeated maximál knee extensions and flexions at an angular velocity of $180^{\circ} / \mathrm{s}$. At each tested velocity the subjects were allowed two trials to become familiar with the equipment. The coefficient of variation for paired observations for strength measurement (total work output) with the Cybex II was: at $60^{\circ} / \mathrm{s}: 0.7 \%$, at $180 \% / \mathrm{s:} 2 \%$.

Assessment of peak oxygen uptake capacity $\left(\dot{V} \mathrm{O}_{2}\right.$ peak). $\dot{V} \mathrm{O}_{2}$ peak was measured with an incremental worktest, using a bicycle ergometer and 
an open spirometric system (Ergopneumotest, E. Jäger, Würzburg, FRG). The workload was increased stepwise from an initial load of $80 \mathrm{~W}$ every $2 \mathrm{~min}$ by $20 \mathrm{~W}$ in women and $30 \mathrm{~W}$ in men. As criterion for $\dot{V} \mathrm{O}_{2}$ peak we considered the leveling-off in oxygen uptake (15).

Muscle biopsy and fixation. The biopsy was taken from vastus lateralis muscle at midthigh level using the technique of Bergström (16). The muscle tissue samples were processed for electron microscopy by fixation in a $6.25 \%$ solution of glutaraldehyde as previously described in detail (17).

Electron microscopy (EM) and morphometry. Two randomly chosen blocks from each biopsy were used for the stereological analysis. The orientation of the sections was essentially transverse with regard to the muscle fiber axis. Capillary number, fiber number and fiber cross-sectional area were estimated at a final magnification of $\times 1,500$ as previously described (12, Fig. 1). Eight micrographs per block and hence 16 micrographs per biopsy were taken in consecutive frames of slotted grids (type R, 100 A, Veco Co., Amsterdam, Netherlands) yielding more than 100 muscle fiber profiles for analysis in each biopsy. A final magnification of $\times 24,000$ was used for estimation of volumes of mitochondria, intracellular lipids, myofibrils and sarcoplasm per volume of muscle fibers (Fig. 2). Sarcoplasm volume density equals total volume density minus total mitochondria density, intracellular lipid density and myofibrillar density. 20 micrographs per block and hence $\mathbf{4 0}$ micrographs per biopsy were taken with a systematic sampling procedure in consecutive frames of 200-square mesh grids. Contact prints of the $35 \mathrm{~mm}$ films were projected on a screen fitted with quadratic line grids. Point counting was performed with an A 100 grid (100 test points) for the low magnification and with a B 36 grid (144 test points) for the high magnification (17).
Parameter estimates were obtained according to standard stereological procedures (17). Total fiber number of the thigh muscle was obtained by dividing the total muscle area by the mean fiber cross-sectional area (18). Total capillary number of the thigh muscle was calculated by multiplying the total muscle area by the capillary number per $\mathrm{mm}^{2}$. Total thigh volumes of mitochondria, lipids, myofibrils, and sarcoplasm were obtained by multiplying the thigh muscle volume by the percentage of intracellular content of mitochondria, lipids, myofibrils, and sarcoplasm.

Measurements of creatinine. Before the training was instituted and at the end of the training period, creatinine was measured in serum and urine by an automated alkaline picrate method (19).

Statistical analysis. Comparisons of the results were performed using the Student's $t$ test for paired observations. The stereological analysis was designed to yield the estimated mean of volume of mitochondria with a standard error of $\sim 10 \%(20)$.

\section{Results}

Estimation of true muscle areas by $C T$. Muscle areas assessed by CT comprise muscle cells and adipose tissue between the muscles. For the estimation of the percentage of fat deposits by means of the method of Grindrod (13) (see formula 1), measurements of muscle density and subcutaneous fat density in normal healthy untrained subjects were necessary. These values of muscle density and subcutaneous fat density assessed by CT in the normal volunteers were $+63 \pm 1 \mathrm{HU}$ and $-108 \pm 3 \mathrm{HU}$,

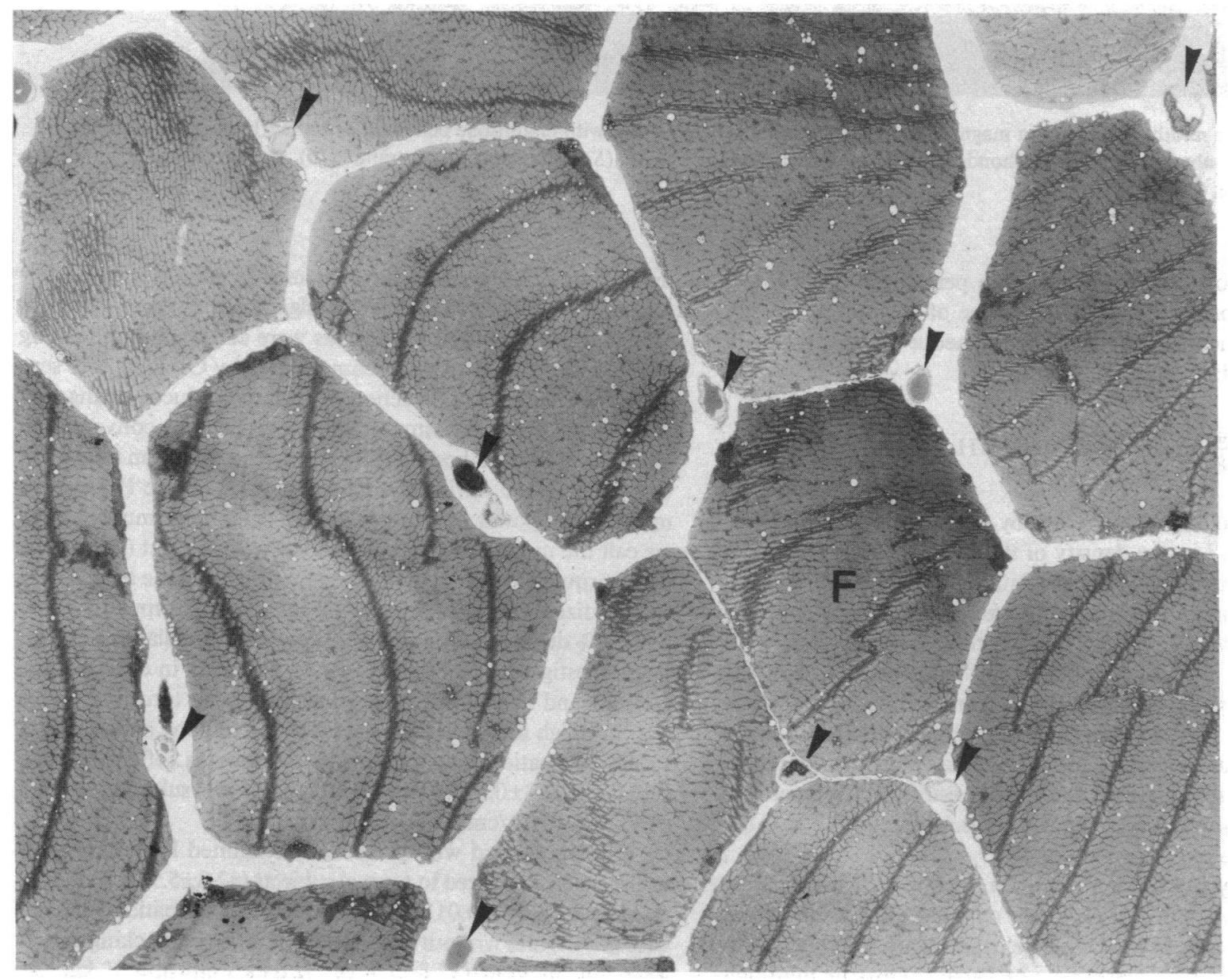

Figure 1. Electron microscopy (EM) of a midthigh biopsy at a magnification $\times 1,060$. F: muscle fibers; $\rightarrow$ capillaries of a normal subject. 


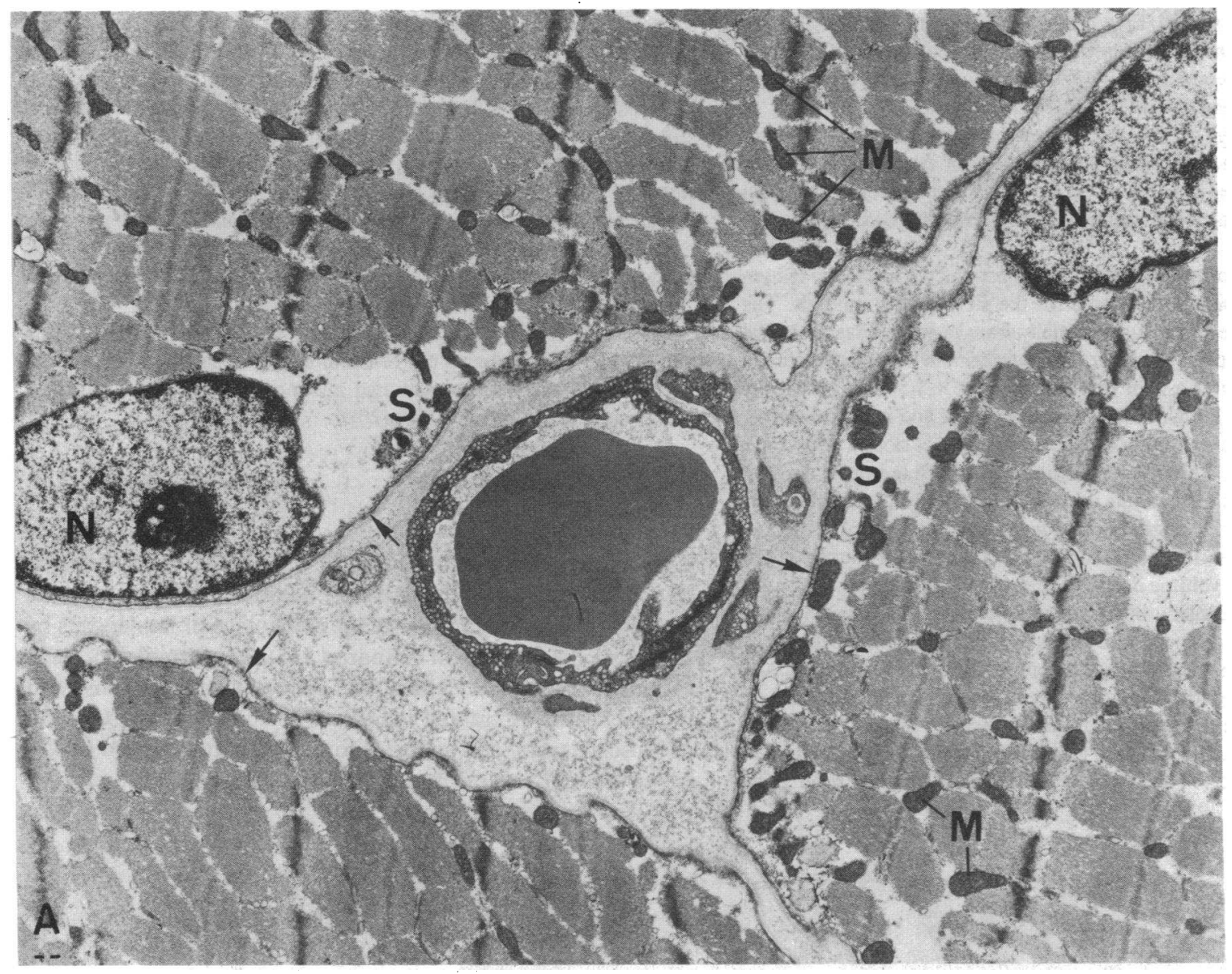

Figure 2. EM of a midthigh biopsy at a magnification $\times 11,300$ of a patient treated with prednisone before (a) and after (b) training. Note the accumulation of subsarcolemmal mitochondria $(M)$ in the subsarcolemmal region $(S)$ in the biopsy after training (b). $\rightarrow$ sarcolemma; $N$ : nucleus of the muscle cell; C: capillary.

respectively. For the estimation of the percentage of fat $\left(f_{\text {fat }} \%\right)$ according to formula 1 , the mean value of the muscle density $(62 \mathrm{HU})$ and the mean value of subcutaneous fat density $(-108$ HU) were used:

$\mathrm{f}_{\mathrm{fat}} \%=\frac{62-\mathrm{H}_{\text {mix }}}{62+108} \times 100=36.5-0.59 \times \mathrm{H}_{\text {mix }}$

$f_{\text {fat }} \%$ was derived from formula 2 by using for each subject the value for $H_{\text {mix }}$, i.e., the density of the thigh muscle. The mean total adipose tissue between the muscles of the thigh was not different in patients when compared with normal subjects $\left(2.5 \pm 1.6 \mathrm{~cm}^{2}\right.$ vs. $\left.2.2 \pm 1.7 \mathrm{~cm}^{2}\right)$. When these mean fat areas were expressed as a percentage of the total thigh muscle area, the values were slightly higher in patients treated with prednisone (2.9\%, range $0.5-7.8 \%)$ than in healthy volunteers $(2.2 \%$, range $0.2-6.3 \%$ ). Thus the estimation of the muscle area without correction for the intramuscular fat deposits results in an intersubject variable overestimation of the true muscle area of 0.2 to $7.8 \%$ of the muscle area, measured by CT.

Influence of isokinetic training on thigh muscle areas, thigh muscle power output, $\dot{V} \mathrm{O}_{2}$ peak and on thigh muscle ultrastructure. The influence of the isokinetic training on the thigh compqnents assessed by CT are given in Table I. The true midthigh muscle area increased and the fat/muscle ratio decreased following the training (Table I). No significant changes were observed when only total thigh areas were considered, indicating that the assessment of thigh components by CT is a more sensitive method for the detection of training induced changes of the thigh than the assessment of the total thigh by conventional anthropometric methods (21). In all subjects the mean total work output increased during the training period (Table I). In order to assess the power output per square centimeter muscle, what we call the muscle efficiency, the total work output $(J)$ and the peak torque $(\mathrm{Nm})$ were divided by the thigh muscle area. These standardized values increased for total work output by more than $20 \%$ during the training period in both populations of subjects investigated $(P<0.001$, Fig. 3). Similarly in eight of nine patients and in eight of nine volunteers peak torque at $60 \%$ per $\mathrm{cm}^{2}$ thigh muscle increased during the training period (mean values for patients on prednisone, before vs. after training: $2.1 \pm 0.4$ vs. $2.3 \pm 0.5 \mathrm{Nm} / \mathrm{cm}^{2}, P<0.05$; normal subjects: $1.9 \pm 0.2$ vs. $2.2 \pm 0.3 \mathrm{Nm} / \mathrm{cm}^{2}, P<0.025$ ).

Patients treated with prednisone exhibited lower $\dot{V O}_{2}$ peak values when compared to normal subjects $(32.8 \pm 5.9$ vs. $40.0 \pm 6.7$ $\mathrm{ml} / \mathrm{min} \times \mathrm{kg}, P<0.01) . \dot{V} \mathrm{O}_{2}$ peak values in the patients treated with $(n=4)$ and without $(n=5)$ beta adrenergic blocking agents were not different $(32.8 \pm 7.7$ vs. $32.6 \pm 4.7 \mathrm{ml} / \mathrm{min} \times \mathrm{kg})$. As 


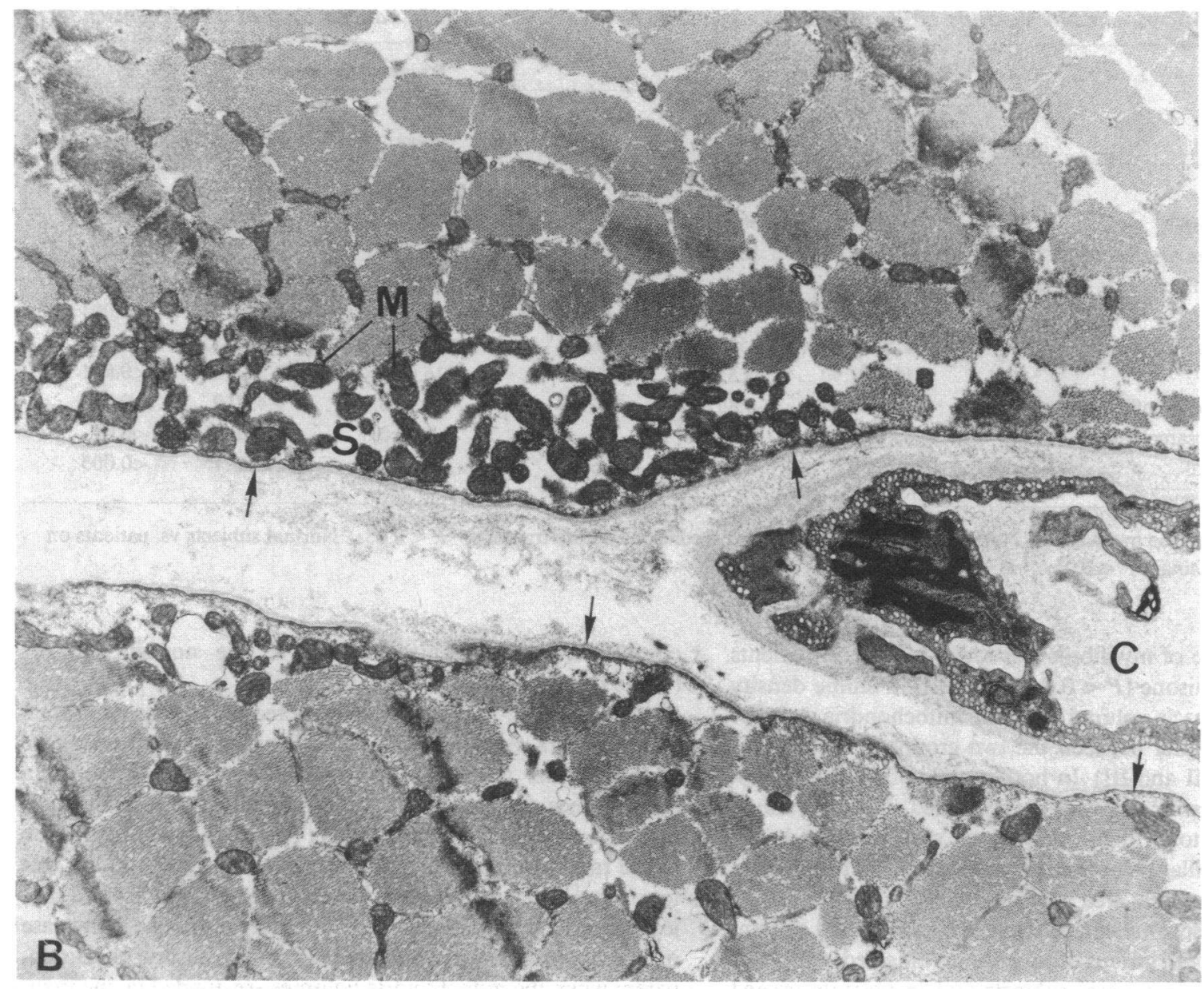

Figure 2 (Continued)

expected the mean maximal workload values on the bicycle ergometer attained during the $\dot{V} \mathrm{O}_{2}$ peak measurements were higher in normal subjects than in patients on prednisone $(191 \pm 43 \mathrm{~W}$ vs. $154 \pm 42 \mathrm{~W}, P<0.01)$ before the training. These values of maximal workload increased during the training period (patients: $+19 \mathrm{~W}, P<0.001$; normal subjects $+24 \mathrm{~W} ; P<0.01, n=8$ ). In glucocorticoid treated patients $\dot{V} \mathrm{O}_{2}$ peak remained unchanged by the training ( $32.8 \pm 5.9$ vs. $34.3 \pm 7.4 \mathrm{ml} / \mathrm{min} \times \mathrm{kg})$, while in normal subjects a slight increase in $\dot{V} \mathrm{O}_{2}$ peak was observed $(40.0 \pm 6.7$ vs. $43.7 \pm 7.4 \mathrm{ml} / \mathrm{min} \times \mathrm{kg}, P<0.05)$.

In Table II the results from the morphometric analysis of the biopsies are given without considering the total thigh muscle area as assessed by CT. In order to get an estimate of the total thigh muscle content of ultrastructural components, the results obtained in Table II were multiplied by the true thigh muscle area assessed by CT (Table III). The morphometrical analysis of the thigh muscle in glucocorticoid-treated patients exhibited a more than $30 \%$ lower mean number of fibers of the thigh muscle when compared with normal subjects before training $(P$ $<0.004$, Table III). Training did not change total thigh muscle fiber number (Table III).

The estimated total capillary number of the thigh muscle was higher by more than $80 \%$ in normal subjects than in glucocorticoid treated patients $(P<0.001$, Table III). The ratio of capillary per square millimeter fiber area (capillary density) is an estimate of the diffusion distance of oxygen from the red blood cell to the mitochondria. This ratio was higher $>40 \%$ in normal subjects than in patients on prednisone (Table II). The number of capillaries of the total thigh muscle area increased in both groups of subjects investigated, however, the difference was only significant for patients taking prednisone (Table III).

When the volume density of myofibrils was analyzed in the biopsies no difference was observed between patients on prednisone and normal subjects (Table II). However, the mean total

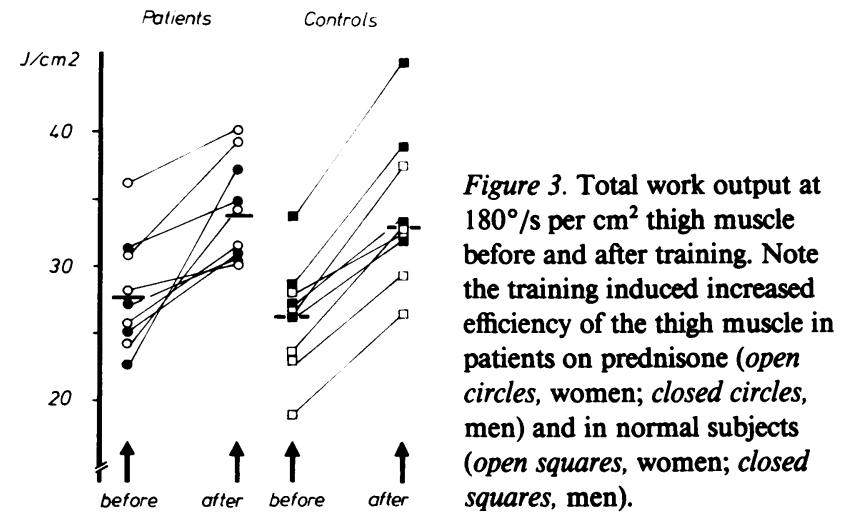




\begin{tabular}{|c|c|c|c|c|c|c|}
\hline & \multicolumn{3}{|c|}{ Normal subjects } & \multicolumn{3}{|c|}{ Prednisone-treated patients } \\
\hline & Before & After & $\begin{array}{l}P \text { value before } \\
\text { vs. after training }\end{array}$ & Before & After & $\begin{array}{l}P \text { value before } \\
\text { vs. after training }\end{array}$ \\
\hline \multicolumn{7}{|l|}{ Number of } \\
\hline Fiber per $\mathrm{mm}^{2}, \mathrm{~mm}^{-2}$ & $396 \pm 70$ & $381 \pm 83$ & NS & $353 \pm 71$ & $351 \pm 79$ & NS \\
\hline Capillaries per fiber area, $\mathrm{mm}^{-2}$ & $499 \pm 68^{*}$ & $530 \pm 37^{\ddagger}$ & NS & $343 \pm 70^{*}$ & $377 \pm 84^{\ddagger}$ & NS \\
\hline \multicolumn{7}{|c|}{ Volume density of intracellular structures (\%) } \\
\hline Myofibrils & $80.1 \pm 1.6$ & $76.5 \pm 4.8$ & $<0.01$ & $78.5 \pm 3.5$ & $73.5 \pm 2.4$ & $<0.001$ \\
\hline Intracellular lipids & $0.50 \pm 0.24$ & $0.56 \pm 0.33$ & NS & $0.72 \pm 0.50$ & $0.65 \pm 0.55$ & NS \\
\hline Sarcoplasm & $15.3 \pm 1.9$ & $18.5 \pm 4.0$ & $<0.01$ & $16.0 \pm 2.4$ & $20.3 \pm 2.1$ & $<0.001$ \\
\hline Mitochondria, intermyofibrillar & $3.5 \pm 0.5$ & $3.8 \pm 0.6$ & NS & $3.9 \pm 0.9$ & $4.4 \pm 0.9$ & $<0.02$ \\
\hline Mitochondria, subsarcolemmal & $0.6 \pm 0.2$ & $0.6 \pm 0.3^{\ddagger}$ & NS & $0.9 \pm 0.6$ & $1.3 \pm 0.4^{\ddagger}$ & $<0.01$ \\
\hline Mitochondria, total & $4.1 \pm 0.6$ & $4.4 \pm 0.7^{8}$ & NS & $4.7 \pm 1.4$ & $5.7 \pm 1.1^{8}$ & $<0.005$ \\
\hline
\end{tabular}

All values are given as the mean \pm SD. Normal subjects vs. patients on prednisone before training: ${ }^{*} P<0.05$. Normal subjects vs. patients on prednisone after training: ${ }^{\ddagger} P<0.05$. ${ }^{\&} P<0.01$.

thigh muscle value of myofibrils was lower by $20 \%$ in patients treated with prednisone $(P<0.04$, Table III). Volume density and total thigh muscle volume of lipids, mitochondria and sarcoplasm did not differ between the two groups of subjects investigated (Table II and III). In both groups of subjects investigated volume density of myofibrils decreased after the training (Table II). When total thigh muscle area was considered, this change in myofibrillar volume density was set off by the changes in the total thigh muscle area measured by CT (Table III).

No training-associated changes in intracellular lipid content were observed in both groups of subjects investigated, while sarcoplasm increased in normal subjects and in patients treated with prednisone by $>20 \%$ (Table II and III). Volume density and total thigh muscle volume of mitochondria were larger at the end than at the beginning of the training period in gluco- corticoid-treated patients but not in the normal subjects (Table II).

The training-induced relative increase in subsarcolemmal mitochondria was more pronounced than the relative increase in interfibrillar mitochondria in patients on prednisone. As a consequence the ratio of interfibrillar/subsarcolemmal mitochondria decreased in the patients (Table III). The mean value of the ratio of interfibrillar/subsarcolemmal mitochondria was lower by $\sim 50 \%$ in patients on prednisone than in normal subjects after the training (Table III). The more pronounced increase in mitochondria content in patients on prednisone is also apparent when the mitochondria volumes are divided by the myofibrillar volumes (Table III).

Thigh muscle function as related to ultrastructure of thigh components and to $\dot{V} \mathrm{O}_{2}$ peak. A linear relationship between total

Table III. Quantitative Midthigh Muscle Ultrastructure in Normal Subjects and in Patients on Prednisone Before and After Training

\begin{tabular}{|c|c|c|c|c|c|c|}
\hline & \multicolumn{3}{|l|}{ Normal subjects } & \multicolumn{3}{|c|}{ Prednisone-treated patients } \\
\hline & Before & After & $\begin{array}{l}P \text { value before } \\
\text { vs. after training }\end{array}$ & Before & After & $\begin{array}{l}P \text { value before } \\
\text { vs. after training }\end{array}$ \\
\hline \multicolumn{7}{|l|}{ Total number of } \\
\hline Thigh muscle fibers $\left(10^{6} \mathrm{~cm}^{-2}\right)$ & $4.85 \pm 1.11^{*}$ & $4.93 \pm 1.27^{\ddagger}$ & NS & $3.35 \pm 0.59^{*}$ & $3.57 \pm 60^{\ddagger}$ & NS \\
\hline Thigh muscle capillaries $\left(10^{6} \mathrm{~cm}^{-2}\right)$ & $6.18 \pm 1.46^{8}$ & $6.95 \pm 1.59^{\prime \prime}$ & NS & $3.40 \pm 1.07^{8}$ & $3.98 \pm 119^{\prime \prime}$ & $<0.02$ \\
\hline \multicolumn{7}{|l|}{ Total volume of midthigh muscle } \\
\hline Myofibrils $\left(\mathrm{cm}^{3}\right)$ & $100.2 \pm 24.4^{\prime}$ & $101.0 \pm 24.3^{* *}$ & NS & $76.9 \pm 18.5^{\prime}$ & $77.6 \pm 19.2^{* *}$ & NS \\
\hline Intracellular lipids $\left(\mathrm{cm}^{3}\right)$ & $0.6 \pm 0.3$ & $0.8 \pm 0.6$ & NS & $0.7 \pm 0.6$ & $0.6 \pm 0.3$ & NS \\
\hline Sarcoplasm $\left(\mathrm{cm}^{3}\right)$ & $19.4 \pm 6.3$ & $24.1 \pm 7.8$ & $<0.01$ & $15.6 \pm 4.3$ & $21.1 \pm 4.3$ & $<0.001$ \\
\hline Mitochondria, interfibrillar $\left(\mathrm{cm}^{3}\right)$ & $4.4 \pm 1.3$ & $5.1 \pm 1.5$ & NS & $3.9 \pm 1.5$ & $4.7 \pm 2.0$ & $<0.01$ \\
\hline Mitochondria, subsarcolemmal $\left(\mathrm{cm}^{3}\right)$ & $0.7 \pm 0.3$ & $0.7 \pm 0.3^{\ddagger}$ & NS & $0.8 \pm 0.6$ & $1.3 \pm 0.5^{\ddagger}$ & $<0.005$ \\
\hline Mitochondria, total $\left(\mathrm{cm}^{3}\right)$ & $5.1 \pm 1.5$ & $5.8 \pm 1.6$ & NS & $4.7 \pm 1.9$ & $6.1 \pm 2.4$ & $<0.005$ \\
\hline \multicolumn{7}{|l|}{ Ratio of } \\
\hline $\begin{array}{l}\text { Interfibrillar/subsarcolemmal } \\
\text { mitochondria }\end{array}$ & $7.3 \pm 3.1$ & $8.2 \pm 5.1^{\ddagger}$ & NS & $6.5 \pm 4.3$ & $3.7 \pm 0.7^{\ddagger}$ & $<0.05$ \\
\hline Mitochondria/myofibrillar area, $10^{-2}$ & $5.0 \pm 0.8$ & $5.6 \pm 1.7^{* *}$ & NS & $5.7 \pm 1.9$ & $7.5 \pm 1.7^{* *}$ & $<0.01$ \\
\hline
\end{tabular}

Values are given as the mean \pm SD. Normal subjects vs. patients on prednisone before training: ${ }^{9} P<0.05 ;{ }^{*} P<0.01 ;{ }^{8} P<0.001$. Normal subjects vs. patients on prednisone after training: ${ }^{* *} P<0.05$; $^{\ddagger} P<0.01$; $" P<0.001$. 


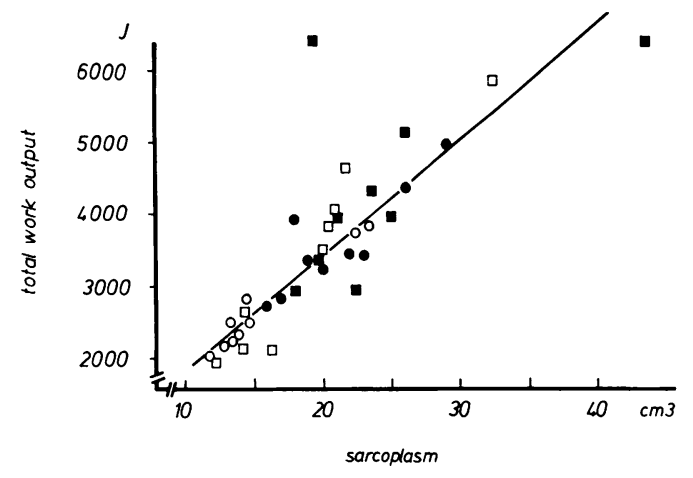

Figure 4. Relationship between total work output at $180^{\circ} / \mathrm{s}$ and sarcoplasm of the thigh muscle before training (open circles, patients on prednisone; open squares, normal subjects). Note that the relationship was preserved by the training (closed circles, patients; closed squares, normal subjects).

work output at $180^{\circ} / \mathrm{s}$ and the area of sarcoplasm within the muscle cells before the training was found $(r=0.86, P<0.001$, $n=18)$. Note that this relationship was not modulated by the training ( $r=0.86, P<0.001, n=18$, Fig. 4). A similar relationship was observed between the muscle area of sarcoplasm and the peak torque values at $60^{\circ} / \mathrm{s}$ measured before $(r=0.83$, $P<0.001, n=18)$ and after the training $(r=0.83, P<0.001$, $n=18)$.

In all nine patients and in eight of the nine normal subjects the total volume of sarcoplasm within the muscle increased concomitantly with the increments in total work output (Tables II and III). In one normal volunteer there was a decrease in the volume of sarcoplasm while peak torque and total work output increased. When this individual was excluded from the analysis, a linear relationship between training-associated increase in sarcoplasm and the increment in total work output at $180^{\circ} / \mathrm{s}(r$ $=0.52, P<0.05, n=17$, Fig. 5) was found. A similar relationship was detected between the training-induced increment in sarcoplasm and the increase in peak torque at $60^{\circ} / \mathrm{s}(r=0.49, P$ $<0.05, n=17$ ).

Total work output increased with increasing total thigh volume of myofibrils (Fig. 6). When all subjects were analyzed as a group before the training was instituted and compared with the results obtained from the same subjects at the end of the training period, two linear relationships with identical slopes but different intercepts were found (before training: $y=38.5 x$

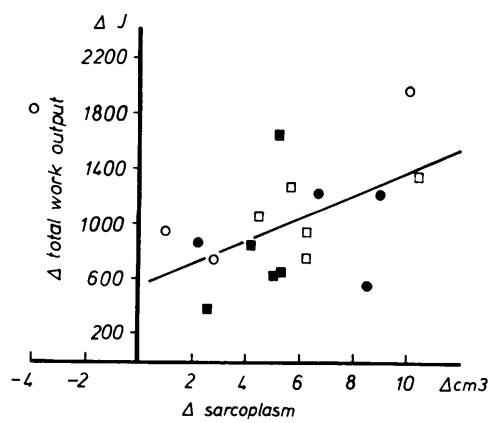

Figure 5. Relationship between training induced changes in total work output at $180^{\circ} / \mathrm{s}$ and training induced increase in sarcoplasm in patients on prednisone (closed circles, men solid squares, women) and normal subjects (open circles, men; open squares, women). In one normal volunteer there

was a decrease in the volume of sarcoplasm, while total work output increased. This individual was excluded from the analysis.

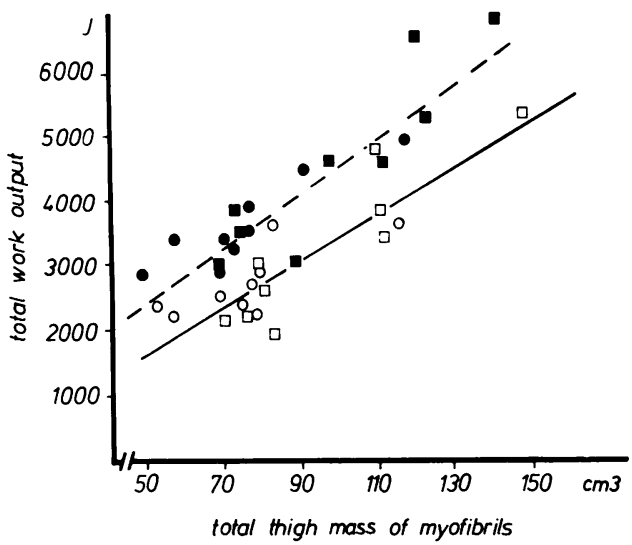

Figure 6. Relationship between total work output at $180^{\circ} / \mathrm{s}$ and total thigh mass of myofibrils in patients on prednisone (open circles) and normal subjects (open squares) before training (-). Note that after training (- - ) a relationship with an identical slope but a different intercept was found, indicating an increased thigh muscle efficiency after training in patients (closed circles) and normal subjects (closed squares).

- 270.9; after training: $y=46.6 x-61.2$, [Fig. 6]), indicating that muscle efficiency was improved by training.

Peak oxygen uptake increased with increasing midthigh muscle area in both patients and normal subjects before the training was instituted $(r=0.94, P<0.001, n=18)$. Moreover $\dot{V} \mathrm{O}_{2}$ peak correlated linearly with the myofibrillar thigh volume ( $r=0.84, P<0.001, n=18)$, sarcoplasm volume $(r=0.66, P$ $<0.003, n=18$ ), total capillary number of the thigh muscle ( $r$ $=0.79, P<0.001, n=18)$ and total mitochondria volume of the thigh muscle $(r=0.62, P<0.007, n=18)$. Only the correlations before training are given. Similar results are obtained when all subjects were analyzed after the training period. These relationships were also significant when only the patients or the normal subjects before or after the training period were analyzed.

A linear relationship between $24 \mathrm{~h}$ urinary creatinine excretion and $\dot{V} \mathrm{O}_{2}$ peak was found in normal subjects and patients on prednisone, before the training was instituted ( $r=0.86, P$ $<0.001, n=18$ ). This relationship was still present after the training period $(r=0.69, P<0.01, n=17)$.

\section{Discussion}

In the present investigation an isokinetic form of training was selected because this form of training is said to be closest to physiological movements of the muscles (22). Renal transplant patients were chosen as a patient population because their glucocorticoid treatment is preventive in nature; they take prednisone to prevent a renal transplant rejection. All other patient populations receive glucocorticoids in order to treat an actual disease state. Therefore, in these patient populations, the influence of prednisone on muscle ultrastructure could be confounded by the underlying disease.

The drawback of studying renal transplant patients on prednisone is the preexisting renal failure. For the following four reasons the changes in muscle structure in our patient population were mostly due to glucocorticoid treatment rather than to the anamnestic uremia. (a) The patients were successfully transplanted 16 to $105 \mathrm{mo}$ (median $60 \mathrm{mo}$ ) before the present in- 
vestigation and their nutritional habits and physical activities had therefore been normalized for a long time period. (b) There are several reports about muscle histology in uremic patients (23-27). In most of the histologically analyzed biopsies from uremic patients, typical myopathic changes, not present in our patients treated with prednisone, could be detected (increased number of central nuclei of muscles fibers [23, 24, 26, 27], myelin figures [24, 25, 27], autophagic vacuoles [20], disrupted filaments $[23,24,27]$ and increased lipofusion [23, 27]). (c) Group atrophy of muscle fibers suggesting neuropathy was also described in uremic patients $(26,27)$. In our nine renal transplant patients treated with prednisone, no such qualitative neuropathic histological signs could be detected. $(d)$ The total volume density of mitochondria in uremic patients was reported to be $>100 \%$ higher than in normal volunteers (27). Our untrained patients treated with prednisone did not exhibit such an uremia-associated increased total mitochondria content of the muscle fibers (Table II), indicating that the muscle changes observed in our patients were rather due to administration of glucocorticoids than to the anamnestic uremia.

The mean number of muscle fibers was lower by $\sim 30 \%$ in patients treated with prednisone when compared with their matched controls (Table III). This decrease in the number of muscle fibers in patients was obtained by dividing the true muscle area, measured by CT, by the mean fiber area, measured by morphometric analysis $(9,18)$. At least two assumptions have to be made in order to calculate the absolute fiber number of a muscle by this method. (a) The tissue sample obtained by biopsy has to be representative for the whole thigh muscle considered by CT before and after training. Whether this is true or not cannot be established on the basis of the present study. For ethical reasons it was not possible to perform several biopsies in the same subject. Note that in the past a great number of investigations using single biopsy specimens from the thigh muscle have been performed in normal subjects and patients, assuming that the muscle biopsy is a representative sample of the thigh muscle $(9,18,23-27)$. (b) The assessment of the size of the muscle fibers and their intracellular components by electron microscopy has to be performed ex vivo after fixation of the tissue. As a consequence of the fixation the various elements may change in size. Therefore differences in the morphometric results between patients and normal subjects might be the consequence of different fixation techniques and/or the result of a different response to the same technique of fixation in tissue obtained from normal subjects and from patients. On the basis of our study design we can only exclude the first caveat.

In the past, glucocorticoid therapy-associated myopathy has been investigated either functionally by measuring muscle power $(10,12,28)$ or histologically by analyzing thigh muscle biopsies $(4-8,29)$. In the present investigation results from a quantitative electron microscopic analysis of vastus lateralis muscle biopsies combined with quantitative measures of total thigh muscle mass were correlated with muscle function. The biological relevance of combining biopsies with a CT measure of the thigh muscle can be shown by three examples. (a) The muscle fiber number per square millimeter was identical in patients on prednisone and healthy subjects (Table II), while total number of thigh muscle fibers was lower by about $25 \%$ before and after training in patients on prednisone (Table III). (b) Total volume of sarcoplasm increased with total work output (Fig. 4), but no significant correlation between the volume density of sarcoplasm and the total work output was found. (c) Volume density of intracellular myofibrils decreased after training in patients and in healthy subjects (Table II), while no training-induced decline of the total myofibrillar mass was observed (Table III). The total myofibrillar mass is biologically a more relevant parameter than the volume density of intracellular myofibrils. This is supported by the observation that total work output increases with increasing total mass of myofibrils (Fig. 6), but not with the volume density of myofibrils.

It was shown that thigh muscle areas (assessed by CT or ultrasound methods) and muscle power increase concomitantly after a moderate physical training $(9,12,30-33)$. In these studies, the percentage increase in muscle power was always two to four times higher than the percentage increment in muscle area (9, $12,30-33)$ and no significant correlation between the relative changes of these two parameters was found $(9,12)$. The more pronounced increase in muscle power relative to the increase in the morphological substrate was explained by a training-induced increased synchronization rate of motor units or an activation of high threshold motor units (34-36). On the basis of the present investigation one has to question the concept, that the traininginduced increase in "efficiency of muscles" is only explained by a functional change and not by an anatomical change, because muscle efficiency and volume of sarcoplasm increased concomitantly after training in patients and normal volunteers.

Mitochondria are the site of oxidative phosphorylation in muscle cells. Morphometric analysis revealed that the intracellular mitochondria content correlates with the activities of oxidative enzymes in muscle cells (37). Therefore the intracellular mitochondria content is an adequate descriptor for muscle cells' potential for aerobic metabolism (37). Considering the total thigh muscle areas of mitochondria before training, no difference was found between patients treated with glucocorticoids and healthy subjects (Table III), suggesting that glucocorticoids do not impair total oxidative phosphorylation capacity of the thigh muscle as shown by Vignos et al. (38) in rats. After training total volume of mitochondria increased in prednisone-treated patients, while no such a significant increase was observed in normal subjects. In the present investigation not only the total volume of mitochondria was assessed but in addition the mitochondria were quantitatively subdivided in those localized between the myofibrils and those in the subsarcolemmal region. The advantage of the morphometric approach used is its potential to quantify the topologic relationships among various structures of energy delivery (capillaries), energy consumption (mitochondria), and mechanical energy production (myofibrils). Subsarcolemmal mitochondria are localized in the periphery of the muscle cell. For an individual muscle cell, an increased subsarcolemmal mitochondria content might be an advantage due to their proximity to the capillary network. Before training the ratio of interfibrillar to subsarcolemmal mitochondria of the total thigh muscle was slightly (not significantly) lower $(12 \%)$ in patients treated with prednisone when compared with healthy subjects (Table III). After training the ratio of interfibrillar to subsarcolemmal mitochondria decreased significantly in patients on prednisone, while this ratio tended to be increased in normal subjects (Table III). The decrease of the ratio was due to a more pronounced increase in subsarcolemmal than intermyofibrillar mitochondria in patients taking prednisone. The increased total mitochondria content and their preferential increase in the subsarcolemmal region after the training period might reflect an adaptive mech- 
anism helping patients treated with prednisone to compensate functionally their shortage in myofibrils and their decreased number of capillaries within the muscle (Table III).

Patients on prednisone exhibit both a decreased capillary number and a decreased mass of myofibrils. It might be that glucocorticoids diminish the myofibrils by inhibiting protein synthesis $(39,40)$ and the capillary number is diminished as a consequence of a reduced mass of myofibrils. Alternatively, therapy with glucocorticoids reduces the capillary number and as a consequence the myofibrillar mass shrinks. The decreased ratio of capillaries to fiber area in patients on prednisone favors the latter hypothesis (Table II). However, it might be that glucocorticoids affect capillaries and myofibrils to a different extent and override mutual adaptive mechanisms between myofibrils and capillaries.

In conclusion, quantitative analysis of the ultrastructure of striated muscle revealed that patients treated with a low dose of prednisone have a decreased number of capillaries and fibers of the thigh muscle. After a moderate strength training, muscle efficiency increased similarly in both groups of subjects investigated. In normal subjects the increase in "muscle efficiency" was associated with an increase in sarcoplasm, whereas in patients on prednisone the functional improvement was associated with an increment in sarcoplasm, capillaries, and mitochondria content. Thus, a low dose of prednisone does not impede traininginduced improvement of muscle efficiency, but glucocorticoids modulate the ultrastructural response to the training.

\section{Acknowledgments}

The authors wish to acknowledge the excellent technical assistance of Mrs. H. Claassen, Mr. J. Rohrer, Mr. D. Herren, Mrs. B. Schulthess, Mrs. N. Jecker, Dr. Schaffner, and Dr. H. Herren and the excellent secretarial assistance of Mrs. C. Weder and Mrs. V. Hausammann.

Supported by Swiss National Foundation for Scientific Research grants 3.914-0.82 and 3.877-0.85.

\section{References}

1. Müller, R., and E. Kugelberg. 1959. Myopathy in Cushing's syndrome. J. Neurolog. Neurosurg. Psychiatry. 22:314-317.

2. Perkoff, G. T., R. Silber, F. H. Typler, and G. E. Cartwright. 1959. Studies in disorders of muscle: XII. Myopathy due to the administration of therapeutic amount of 17-hydroxy corticosteroids. Am. J. Med. 26: 891-896.

3. Mastaglia, F. L. 1982. Adverse effect of drugs on muscle. Drugs. 24:304-321.

4. Engel, A. G. 1966. Electron microscopic observations in thyrotoxic and corticosteroid-induced myopathies. Mayo Clin. Proc. 41:785-796.

5. Afif, A. K., R. A. Bergman, and J. C. Harvey. 1968. Steroid myopathy. Clinical, histologic and cytologic observations. Johns Hopkins Med. J. 123:158-174.

6. Golding, D. N., S. M. Murray, G. W. Pearce, and M. Thompson. 1961. Corticosteroid myopathy. Ann. Phys. Med. 6:171-179.

7. Walsh, G., D. De Vivo, and W. Olson. 1971. Histochemical and ultrastructural changes in rat muscle. Occurrence following adrenal corticotrophic hormone, glucocorticoids and starvation. Arch. Neurol. 24: 83-93.

8. Horber, F. F., H. Hoppeler, D. Herren, H. Claassen, H. Howald, C. H. Gerber, and F. J. Frey. 1986. Altered ultrastructure and mixed fiber type atrophy of skeletal muscle in renal transplant patients treated with prednisone. Kidney Int. 30:411-416.

9. Lüthi, J. M., H. Howald, H. Claassen, K. Rösler, P. Vock, and H.
Hoppeler. 1986. Structural changes in skeletal muscle tissue with heavy resistance exercise. Int. J. Sport Med. 7:123-127.

10. Horber, F. F., J. R. Scheidegger, B. E. Grünig, and F. J. Frey. 1985. Thigh muscle mass and function in patients treated with glucocorticoids. Eur. J. Clin. Invest. 15:302-307.

11. Horber, F. F., R. M. Zürcher, M. A. Crivelli, G. Robotti, and F. J. Frey. 1986. Altered body fat distribution in patients with glucocorticoid treatment and in patients on long-term dialysis. Am. J. Clin. Nutr. 43:758-769.

12. Horber, F. F., J. R. Scheidegger, B. E. Grünig, and F. J. Frey. 1985. Evidence that prednisone-induced myopathy is reversed by physical training. J. Clin. Endocrinol. Metab. 61:83-87.

13. Grindrod, S., P. Tofts, and R. Edwards. 1983. Investigation of human skeletal muscle structure and composition by X-ray computerised tomography. Eur. J. Clin. Invest. 13:465-468.

14. Scott, S. G. 1984. Current concepts in the rehabilitation of the injured athlete. Mayo Clin. Proc. 59:83-90.

15. Astrand, P.-O., and K. Rodahl. 1986. Textbook of Work Physiology. McGraw-Hill Book Co., New York. 354-390.

16. Bergström, J. 1962. Muscle electrolytes in man. Scand. J. Clin. Lab. Invest. 14(Suppl. 68):11-12.

17. Hoppeler, H., P. Lüthi, H. Claassen, E. R. Weibel, and H. Howald. 1973. The ultrastructure of the normal human skeletal muscle. A morphometric analysis on untrained men, women and well-trained orienteers. Pfluegers Arch. Eur. J. Physiol. 344:217-232.

18. Häggmark, T., E. Jansson, and B. Svane. 1978. Cross-sectional area of the thigh muscle in man measured by computed tomography. Scand. J. Clin. Lab. Invest. 38:355-360.

19. Hudsan, H., and A. Rapoport. 1968. Estimation of creatinine by the Jaffe reaction. A comparison of three methods. Clin. Chem. 44: 222-238.

20. Mathieu, O., L. M. Cruz-Orive, H. Hoppeler, and E. R. Weibel. 1981. Measuring error and sampling variation in sterology: comparison of the efficiency of various methods for planar image analysis. J. Microscopy. 121:75-88.

21. Heymsfield, S. B., R. P. Olafson, M. H. Kutner, and D. W. Nixon. 1979. A radiographic method of quantifying protein-calorie undernutrition. Am. J. Clin. Nutr. 32:693-702.

22. Elliot, J. 1978. Assessing muscle strength isokinetically. JAMA (J. Am. Med. Assoc.). 240:2408-2409.

23. Bundschu, H. D., and W. Schlote. 1974. Elektronenmikroskopische Untersuchungen der Skelettmuskulatur bei terminaler Niereinsuffizienz. J. Neurosurg. Sci. 23:243-254.

24. Floyd, M., D. R. Ayyar, D. D. Barwick, P. Hudgson, and D. Weightman. 1974. Myopathy in chronic renal failure. Q. J. Med. 172: 509-524.

25. Bellinghieri, G., V. Savica, A. Mallamace, C. Di Stefano, F. Consolo, L. G. Spagnoli, S. Villaschi, G. Palmieri, M. Corsi, and F. Maccari. 1983. Correlation between increased serum and tissue L-carnitine levels and improved muscle symptoms in hemodialyzed patients. Am. J. Clin. Nutr. 38:523-531.

26. Ahonen, R. E. 1980. Light microscopic study of striated muscle in uremia. Acta Neuropathol. 49:51-55.

27. Shah, A. J., V. Sahgal, S. P. Quintanilla, V. Subramani, H. Singh, and R. Hughes. 1983. Muscle in chronic uremia. A histochemical and morphometric study of human quadriceps muscle biopsies. Clin. Neuropathol. 2:83-89.

28. Rothstein, J. M., A. Delitto, D. R. Sinacore, and S. J. Rose. 1983. Muscle function in rheumatic disease patients treated with corticosteroids. Muscle \& Nerve. 6:128-135.

29. Khaleeli, A. A., R. H. T. Edwards, K. Gohil, G. McPhail, M. J. Rennie, J. Round, and E. J. Ross. 1983. Corticosteroid myopathy. A clinical and pathological study. Clin. Endocrinol. 18:155-161.

30. Houston, N. E., E. A. Froese, P. St. Valeriote, J. Green, and D. A. Ranney. 1983. Muscle performance, morphology, and metabolic capacity during strength training and detraining: A one leg model. Eur. J. Appl. Physiol. 51:25-35. 
31. Coyle, E. F., D. C. Feiring, T. C. Rotkis, R. W. Cote III, F. B. Roby, W. Lee, and J. H. Wilmore. 1981. Specificity of power improvements through slow and fast isokinetic training. J. Appl. Physiol. 51: 1437-1442.

32. Pipes, T. V., and J. H. Wilmore. 1975. Isokinetic vs isotonic strength training in adult men. Med. Sci. Sports. 7:262-274.

33. Lesmes, G. R., D. L. Costill, E. F. Coyle, and W. J. Fink. 1978. Muscle strength and power changes during maximal isokinetic training. Med. Sci. Sports. 10:266-269.

34. Moritani, T., and H. A. de Vries. 1979. Neural factors versus hypertrophy in the time course of muscle strength gain. Am. J. Phys. Med. 58:115-130.

35. Milner-Brown, H. S., R. B. Stein, and R. G. Lee. 1975. Synchronization of human motor units: possible roles of exercise and supraspinal reflexes. Electroencephalogr. Clin. Neurophysiol. 38:245-254.

36. Sale, D. G., A. J. McComas, J. D. MacDougall, and A. R. M.
Upton. 1982. Neuromuscular adaptation in human thenar muscles following strength training and immobilization. J. Appl. Physiol. (Reprint Environ. Exercise Physiol.). 53(2):419-424.

37. Reichmann, H., H. Hoppeler, O. Mathieu-Costello, F. von Bergen, and D. Pette. 1985. Biochemical and ultrastructural changes of skeletal muscle mitochondria after chronic electrical stimulation in rabbits. Pfluegers Arch. Eur. J. Physiol. 404:1-9.

38. Vignos, P., and R. Greene. 1973. Oxidative respiration of skeletal muscle in experimental corticosteroid myopathy. J. Lab. Clin. Med. 81: 365-377.

39. Kelly, F. J., and D. F. Goldspink. 1982. The differing responses of four muscle types to dexamethasone treatment in the rat. Biochem. J. 208:147-158.

40. Shoji, S., and R. J. T. Pennington. 1977. The effect of cortisone on protein breakdown and synthesis in rat skeletal muscle. Mol. Cell. Endocrinol. 6:159-169. 